\title{
Role of Sovereign Indicators in Performance of Stock Market of Pakistan
}

\author{
Jahanzaib Alvi", Muhammad Rehan, Saad Khatri \\ Mohammad Ali Jinnah University, Department of Management Sciences Karachi, Pakistan \\ *Corresponding author: jahanzaib.alvi123@yahoo.com \\ Received January 11, 2019; Revised February 21, 2019; Accepted March 12, 2019
}

\begin{abstract}
The rationale of this research is to determine the influence of macroeconomic indicator (Interest Rate, Inflation Rate, and Exchange Rate) on KSE-100 Returns, 6 month Karachi Interbank Offered Rate (KIBOR) is taken as proxy of the interest rate, Consumer Price Index (CPI) is taken as proxy of the inflation rate, PKR to Dollar rate is take as representative of the exchange rate, the aim of this study is that, how Macroeconomic factors impact equity returns of the stock market in this research the time series data of 14 years was selected from January 302004 to February 102017 on monthly basis, whereas in this tenor the data of financial crisis is also included, Multiple Regression model is examined to test the hypothesis, entire data is collected from the reliable source, to test the multiple regression, software EVIEWS version 9.0 is used, the findings reveal that there is weak relationship between the Independent variables \& Dependent Variable variables, however inflation rate have insignificant negative correlation with KSE-100 returns, interest rate and exchange rate both have negative significant relationship with KSE-100 returns, while investing into stock market of Pakistan investor must considered interest rate and exchange rate to earn lucrative profit, due to lake of resource this research could not cover the entire economic indicators and also could not stretched the tenor of 13 years, if any future research is conducted, so more variables can be taken to generate better results.
\end{abstract}

Keywords: interest rate, inflation rate, exchange rate, KSE-100 Index, KIBOR

Cite This Article: Jahanzaib Alvi, Muhammad Rehan, and Saad Khatri, "Role of Sovereign Indicators in Performance of Stock Market of Pakistan." Journal of Finance and Economics, vol. 7, no. 2 (2019): 52-61. doi: $10.12691 /$ jfe-7-2-2.

\section{Introduction}

Macroeconomics influence the performance of the stock market, most investor consider these macroeconomics variables while they invest on the stock markets, so that the most focused macroeconomics variables are Interest rate, exchange rate and inflation rate which derived the entire the economic at every aspects. And the entire performance of the stock market is affected by the macroeconomics variables. above mentioned variables are taken in this research as proxy of the macroeconomics, Interest rate is understand as the cost of borrowing, interest rate is used as the discount rate for discounting any future cash flows for capital budgeting, an additional amount which is charged as the cost of the borrowing that is called as Interest rate in financial term, basically it is set by the State Bank under the monetary policy to stable the economic growth, Exchange Rate is the measure of any currency worth around the world, that is value of any specific currency with its actual to another currency after conversion, inflation refers to the rising of general level of Prices and good service within specific country along with the Purchasing power is falling as well, this is also duty of the State Bank to control the inflation and must avoid deflation, these variables keep vital rule to make any economy stable and run it smoothly, further stock returns are very effected by their movement.

Stock market is a place where listed companies issue their share to get investment and these share are traded via exchange market or over the counter market, this is also known Capital Market \& Equity Market, this is considered the most important factor of the free market economy within any country, The Stock Exchange is always feasible source of investing, investors tent to grow the wealth and possession, stock market allows investor to access capital by giving a piece of ownership of their company to the investors.

Interest rate is observed to have inverse relationship with the stock return and exchange rate too, similarly exchange rate had inverse relationship with the stock returns, this have been witness in many research in past, interest rate and exchange rate had negative association with stock market index in both context long run and as well as short run, this relationship warn the policy enactors while planning and it also give guidance to investors for prudential investing in equity market, hence many studies define that there influence of inflation rate is seems to be insignificant [1]. The core variables for the macroeconomics reflect the performance of the entire industries and this influence the stock market too, this 
macroeconomics factor always monitor by the prudent investor who get the most of this variables, and recognize threat and opportunity, interest rate, exchange rate and inflation perform vital rule to establish healthy economy and these variables are the index of economy growth. Increase in the interest rate become reason to decrease in stock returns due to Required Rate of Return (RRR) on the stock returns rise that Decrease in stock returns. Moves of the monetary policy makers have very significant influence on the stock returns and ups and down of interest rate indicates good or worse information for prudent investors. in this research macroeconomic factor like Interest Rate, Exchange Rate and Inflation is taken as the independent variable and Stock Return is taken as the dependent variable, therefore the main objective are given below, To find the influenced of the Interest Rate in the on the Stock Return, To find the influenced of the Exchange Rate in the on the Stock Return, To find the influenced of the Inflation Rate in the on the Stock Return this are the main objectives.

Khan, et al, [1] conducted research, to find out the association amid money market rate, inflation rate and foreign currency rate on stock return, whereas they took the sample size of 10 years from 31st July to 30th 2010 to test hypothesis, the model of multiple regression has been used to test the hypothesis, and the findings reveal that there is weak association amid the Independent variables \& Dependent Variable, effect of money market rate and inflation rate found insignificant, although the impact of exchange rate is negative on the stock return, or it can be said like there is inverse association amid exchange rate and stock returns.

Bashir and Hassan [2] together investigated a study, to determine the association money market rate and stock returns in the UAE the time series data was covering the period of 1990 to 1994 to test the hypothesis, simple OLS test was applied, findings reveal that interest rate fluctuation had significant invers (negative) relationship with stick returns of the banking sector.

Nishat and Shaheen [3] conducted a research to determine the association amid the macroeconomic indicators and KSE-100 stock returns, hence they took data on quarter wise basis from the 1973 to 2004 to test the hypothesis, macroeconomics indicators are Industrial Production Index, Inflation, Broad Money, Value of an Investment and Money Market rate applied with error correction model and Granger Causality test was also applied, findings reveal the long run relationship amongst these variables, therefore the study found that the IPI and Inflation rate were highest positive and negative factors respectively, there was also causal relationship amid interest rate and stock returns.

Hence whereas above mention research conducted research on the different time horizon I found the gap to conduct the most recent research to determine the relationship amongst the economics indication i,e (Interest Rate, Inflation Rate, and Exchange Rate) with stock market returns.

\subsection{Problem Statement}

$[1,4,5,6,7]$ these all authors had the same problem such as Stock Exchange heartbeat of economy, it is index of the growth and development of the any country, there is no economy with the stock exchange in this current ultramodern world stock market performs very vital rule in the development and growth of any economy, All the listed companies offer investor a chance to make money by investing with their companies so that listed companies get the capital and they reinvest it for manufacturing and services purpose and make they make profit as well like the investor, stock market shows performance of the companies in the PSX-100 Index and so on, this circulation of money grow the economic if it is being invested well, in this process if there is any fluctuation that could harm of benevolent for the economy and that fluctuation can be happened by the fluctuation with in macroeconomic factor which may be Interest Rate, Exchange Rate and Inflation Rate, so the problem arisen here to measure this either stock market have been impacted by this variables of other reasons, the rationale of this research is to determine the fluctuation of the stock market either macroeconomics factors any behind this fluctuation or some other variables.

\subsection{Research Question}

Macroeconomic factor are the indicator of the decline and growth of any country, this factors influenced all activities within the circle of the economics of any state and without economy there is not any state, economics means science and art of the wealth, and in the current era wealth of any country is measure by the stock exchange situation because every small and big investor invest their money with stock exchange so that this money is become the blood of the economy and this gives opportunity to economic growth and development, so the rationale of this research is to determine the influence of macroeconomic factors on the stock returns. Such as

- Is there any Influence of the Interest Rate on the Stock Returns

- Is there any Influence of Inflation Rate on the Stock Returns

- Is there any Influence of the Exchange Rate on the Stock Returns.

\subsection{Research objective}

In this research fluctuation with the stock returns will be focus and the main objective is to find out the rationale because of which the fluctuation is occurred with the stock returns, hence macroeconomic factors are supposed to be the main variable which influence any country's stock market so that in this research macroeconomic factor like Interest Rate, Inflation and Exchange Rate is taken as the independent variable and Stock Return is taken as the dependent variable, therefore the main objective are given below,

- To find the influenced of the Interest Rate on the Stock Returns

- To find the influenced of the Inflation Rate on the Stock Returns

- To find the influenced of the Exchange Rate on the Stock Returns. 


\subsection{Significant of the Study}

The stock market of any country keeps the value of heart for the economy, so that it plays very important role to progress the country, it is the place where securities (Share, Sukuk, Bond, TFC, etc.) are bought \& sold, people make investment in the stock exchange to earn lucrative profit, where there is a profit where is a risk, basically risk of the investment most refers to the economy condition, which is measure by macroeconomic indicators such like interest rate, inflation rate, exchange rate, and so on, these factor perhaps impact on the performance of the stock exchange, those country which are having very volatile economy the discourage investor (local investor \& foreign investor) to invest into stock exchange, so to make a room to understand that how does macroeconomic factor impact the universe of the stock market this research was conducted, this research might be helpful investors (to make sound decision before investing into stock exchange), students, teacher, broker, fund managers, and all those people who are concern with the stock market of the Pakistan. For this purpose monthly data of six month Treasury bill rate, exchange rate as value PKR to Dollar and inflation as consumer Price Index (CPI) from 30th January, 2010 to January 30th 2017 is selected. Stock returns is calculated like $\mathrm{SR}=\mathrm{LN}(\mathrm{P} 1 / \mathrm{P} 0)$, whereas $\mathrm{SR}$ is stock return, $\mathrm{P} 1$ new price, $\mathrm{P} 0$ is previous price.

\subsection{Research Gape}

The main limitation of the study due to time constraint I could not take data for many years if anyone want to conduct the research he could starched the time scale of the research and precede this research for future.

\subsection{Structure of the Study}

The structure of the study involves, literature review, conceptual framework, research methodology (research approach, research design, research method research techniques and rest of the essential sections), results and discussions, conclusions, recommendations, references and appendix.

\section{Literature Review}

Kanwal \& Nadeem [8] studied long term association amid Macroeconomics variables and Pakistan Stock Exchange indices, the took data quarter wise from the tenor of 1973-2004 for their research, Macroeconomics variables (Gross Domestic Product (GDP) Index, Inflation, Broad Money, Value of an Investment Earning and Interest Rate were tested along with error correction models as well as Granger Causality Technique, findings were given on the basis of these macroeconomic variables, the findings reveal that there is long run relationship between amongst these variables it has also indicated that Gross Domestic Product (GDP) and inflation are largest positive and negative factors respectively. They also had casual association between stock exchange and Money Market Rate.
Maysami, Loo, \& Koh, [9] have investigated that co integration amid macroeconomic variables and stock exchange sector indices as well as stock market indexes, sector indices comprise on Financial sector indices, Property Sector Indices and Hotel Sector Indices as per monthly data from tenor of January 1989 to 2001, Money Market Rate both short run and long run, Gross Domestic product, Price Level, Exchange Rate and Money Market Supply (Both M1 \& M2) were tested via adopting co-integration and Vector Error Correction Model (VECM). Results revealed that there is strong relationship stock index and Property Index along with all variables. While strong association with specific variables only was established for financial sector indices and hotel sector indices.

Hyde [10] indulges in the investigation about sensitivity of Stock Returns 33 industries portfolio of 4 European countries Economics to Exchange Rate, Money Market Rate and Market Risk. For this research he took data from the time period of January 1973 to December 2004, the findings revealed that Exchange Rate and Market Risk both were seemed very significant and positive for all four countries economic, but interest rate risk was positively significant for France \& Germany.

Blanchard [11] have investigated that there least impact of Interest rate, Exchange Rate and inflation on stock returns, he further elaborate the relationship of output, stock market and interest rate, meanwhile he identified that as much higher stock money as much lower the interest rate which give sense that least cost of capital and which turns into good stock returns, Blanchard described that frequent change in the policies becomes the reason of change in the stock market due to real money market rate and expected profit, it was concluded by him that the flexible policies may impact nominal money which drag to change in the sto0ck returns.

Kaul [12], have come across with the consequences of the association amongst exchange rate, interest rate and inflation on stock returns, he stated inverse relationship between among stock returns and anticipated inflation and positive association among stock returns and real activities. Negative hypothesis were generated for testing and data was selected from the tenor of 1926-1940. It was concluded that this negative association may be descried via understanding the equilibrium process in financial sector which depends on money demand and supply impacts.

Anderson [13], have dig into the relationship amongst the variable of macroeconomics factors and stock returns of US stock Exchange. A research empirically tested Sensitivity Commercial Banks' stock return, interest rate and exchange return were taken as independent variables and stock return was taken as dependent variables, and target population was US Commercial Banks along with the tenor of 1975 to 1987 , results reveal that exchange rate has inverse relationship with stock return and interest rate has positive relationship with stock return of US commercial banks.

Lobo [14] have investigated the impact of money market rate at stock rate. He determined that, the behavior of stock rate after the federal funds rate the asymmetry with the rate while adjusting get narrow, even he 
determined that, there is very rapid response by the stock market at the rumors and the news of over pricings as compare to the news of under pricings. Last not least he finally came up with conclusion that, the target rate announcement had significant effect on the stock prices. Which convey the news to the stock exchange.

Devereux, Lane, \& Xu, [15] together had a study on the synonyms of monetary policy. Whereas financial crisis perform very vital role to enhance the monetary policies with emerging markets, further they have studies that the exchange rate flexibility for its implementation. The methodology of the research involve the nominal regidities, borrowing constraints at the investments and the ups and down of exchange rate while importing goods and services, they set some assumptions such like there could be a delay happened in the exchange rate fluctuations at the time of importing goods and services., a minor fluctuation of the exchange rate could deduce nominal interest rate which led to the higher borrowing impacts, they determined that well established properties of inflation triggering could be examined by the pass through of the imported goods prices.

Khrawish, Siam, \& Jaradat, [16] determined market capitalization rate and money market rate for the market of Jordan namely Amman Stock Exchange, both the variables were crucial for their study for impacting entire country's economy. To check the association amid these variables, a random sample was taken from 1990 to 2008, and ordinary least squares (OLS) technique was used to test the research hypothesis. The findings of the research witness a significant positive association and the very first hypothesis (A) had negative relationship between the interest rate and market capitalization rate which was rejected. They further found that there is positive association between the market development rate and market capitalization rate, so this hypothesis was also rejected, at end the came up with the conclusion that the government keeps vital role to inverse in the financial market of Jordan.

Rano \& Bayero, [17] conducted a research on the fluctuation of the stock returns and the impact of the inflation rate, in this study heterosckedasticity technique was applied to look into the association of the stock market of Nigeria and Ghana. Technique of normality of the data which is perhaps (kurtosis, Skewness, and Jarque Bera) and descriptive statistics witnessed that the average stock returns were positive but much volatile for the Nigerian stock market Ghana stock market as well, the finding of the research, by the models returns that the volatility of market of the Nigeria market was significant but it was not significant for the market of the Ghana, market volatility is influenced by the inflation in the both countries, if inflation increased so market volatility will also go along with the inflation in the same direction, but there is no significant relationship of market volatility and inflation in Ghana Market.

Mundell [18] studied the relationship and inflation rate, he argued that the expected inflation rate may cause to increment in the money market rate, interest rate could have a little fluctuation due to disestablished cost of livings, this is due to interest rate increase if the prices increase but it does increase as much as higher as it should be, that was the assumption of the study that the real profit could be capitalized at real interest rate. Inflation may be the reason of difference between money interest rate and real interest rate, and hence the gape is found in these differences.

Aydemir \& Demirhan [19] studied together to determined influence of macroeconomic factors on the stock market of the Turkey, the sample was select between 2001 to 2008 to test the hypothesis, they applied the traditional approach, which had the assumption that the stock market is impacted by the exchange rate, Augmented Dicky Fuller technique was used which witnessed the data is in integrated order, and causality technique determined that bid rectional causality between exchange rate and stock prices at Bosra Stock Exchange (Turkey), the findings reveal that there is positive relationship between the exchange rate and stock prices.

Muhammad, Rasheed, \& Husain [20] had a research with South Asian countries such like Pakistan, India, Bangladesh, and Sri Lanka, to determine the effect of exchange rates on the stock Returns, the study conclude that the relationship within the all countries either the long run of the short run fluctuation in the exchange rate. In this research data was collected on the month wise for six years, in this research, the findings reveal that there is no relationship in both section long run and short run between exchange rate and stock returns within aforementioned countries.

Chaudhry \& Young [21] conducted a research and his findings reveal that there is a correlation amongst the stock prices and other macroeconomic indicators such like foreign exchange rate, foreign reserve, whole sale price index (WPI), industrial Production Index (IPI), broad money and gross fixed capital information. The results unveil that foreign exchange rate and broad money had positive association with stock returns, capital formation and increase in production were insignificant association with stock returns. So findings reveal that earning undefined profit is not in the control of the investors it totally depends on the volatility of with economic indicators, so investor may not earn undefined profits by getting the information of the market in their hands.

Khan et al. [1] conducted research, to find out the relationship between interest rate, inflation rate and exchange rate on stock return, whereas they took the sample size of 10 years from 31st July to 30th 2010 to test hypothesis, multiple regression model was used to test the hypothesis, and the findings reveal that there is there is weak relationship between the Independent variables \& Dependent Variable variables, the impact of interest rate and inflation rate is insignificant, although the impact of exchange rate is negative on the stock return, or it can be said like there is inverse relationship between exchange rate and stock returns.

\subsection{Theoretical Framework}

Stock market is a place where listed companies issue their share to get investment and these share are traded via exchange market or over the counter market, this is also known Capital Market \& Equity Market, this is considered the most important factor of the free market economy within any country, The Stock Exchange is always feasible source investors to grow the wealth and 
possession, stock market allows investor to access capital by giving a piece of ownership of their company to the investors.

The rate on which the good and services are sold on the general standards of the price set by the by potential market, to control inflation and deflation the state bank set the policies, is because while the time of inflation the price of goods rise and the purchasing power of the people decrease, this is very damageable for any economy, this is prime responsibility of the state bank to control inflation and deflation,. There are different ways to calculate inflation rate such like industrial production index (IPI), whole sale price index WPI), service price index, (SPI) and consumer price index (CPI), hence to calculate CPI in the Pakistan, a basket of commodities is made and have comparison with the price on that basket on yearly basis, this basket consist 374 items of the commodities with aggregate price level in 35 mega cities of Pakistan, although SPI in measure on the weekly basis which covers 17 mega cities of the Pakistan, WPI basically is measure on those item which are consumed on the primary and the secondary level, this information is directly collected from the country's wholesale market of the companies, this method may covers the mega group which comprised on 425 items of the commodities

The value of local currency in the foreign world is called the exchange rate, exchange rate keeps to aspects the worth of currency at homeland and out of homeland (foreign), it could be quoted indirectly or directly. In this research Pak Rupee to American Dollar exchange rate is taken to find the relationship of exchange rate on the stock returns, it is very understood that the American Dollar is treated as international currency so at most foreign transaction this is used as currency exchange, if our beloved Country Pakistan export more we will get more PKR because Dollar rate is high enough in the Pakistan.

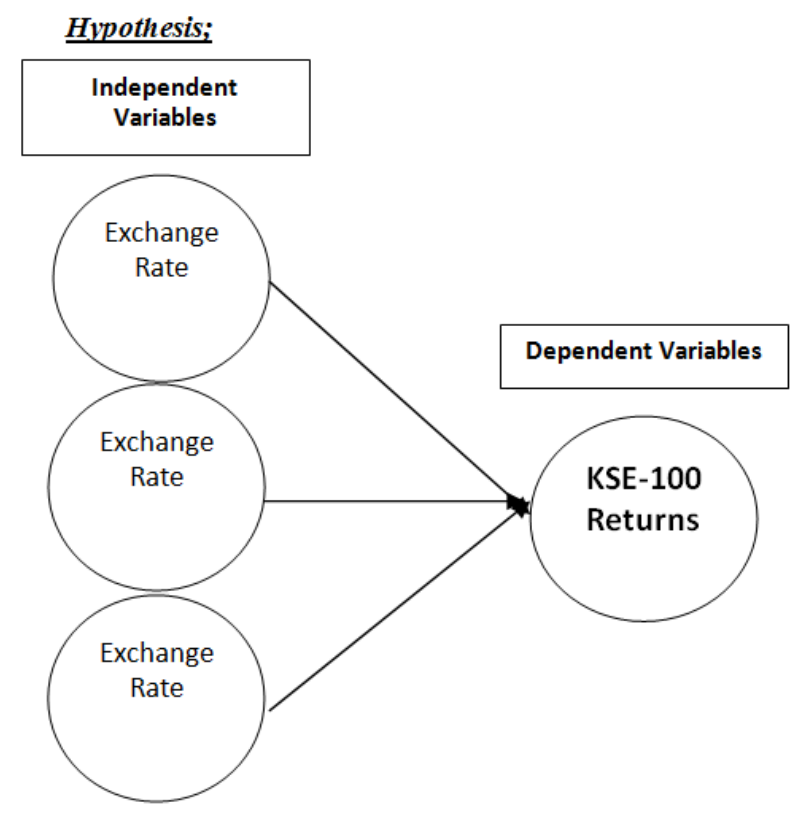

The proportion of a loan that is charged as interest to the borrower, typically expressed as an annual percentage of the loan outstanding. Interest Rate is the cost of lending and borrowing money, state bank of Pakistan (SBP) issue the monetary policy, in which interest rate keep very important worth, it is also nuts and bolts of economy of any country, interest rate may be nominal interest rate, real interest rate, or market Interest Rate, nominal interest rate is unadjusted to inflation hence real is adjusted with inflation rate, in this research 6 month KIBOR Rate is taken as proxy of the interest rate, KIBOR is The Karachi Interbank Offered Rate, or KIBOR, is the average interest rate at which term deposits are offered between prime banks in the Pakistani wholesale money market or interbank market.

\section{Research Methodology}

Research Methodology refers to procedure used to conduct business research; it gives approach to analyzed result for specific research problem for what entire research is being conducted, the research methodology gives track, road map, integration and meaning for generating authentic results and makes result useful for all stakeholders for that research, an appropriate methodology can make sound results or vice versa, that's why methodology keeps the value of heart in the body of research.

\subsection{Research Philosophy}

The Philosophy of this research is mainly based on positivism side due to the study based on the research belongs to natural phenomena \& the entire information about this study was driven from authentic reason and logics.

\subsection{Research Approach}

There are two approaches to conduct a research, Inductive approach is also known as primary research approach, which refers to basic research where new idea, new thesis, and new logic is given for that first hypothesis are to be generated and later gives finding this approach may be count in Qualitative research. Deductive approach is totally inverse of the Inductive approach, this approach is also known as secondary research practices, herewith deductive approach already proposed hypothesis are adopted and research again than gives findings on these hypothesis, deductive approach is might called as Quantitative approach, so this research is secondary research and deductive approach is used to justify the result of this report, hence number of research have been conducted on the same variable as used in this research, that is why this research methodology comes up with secondary research approach methodology which is mainly deductive.

\subsection{Research Design}

\subsubsection{Research Strategy}

As this research is secondary research, the data is collected by archival data from different sources where archival data is available for the result.

\subsubsection{Choice}

In this research Mono Method is used because this research is quantitative based research. 


\subsubsection{Time Horizon}

This research is basically being conducted on the basis of cross sectional time period study. Where number of research, articles, lectures, blogs, and report were studied and most of the theme of this research is adopted from these valuable assets, for this research there were very limited and specific time, within the time the research is to be conducted.

\subsubsection{Population}

The sample is take from the archival data, from January 302004 to February 10 2017, from the historical data, all though it could be stretched but due to unavailability of resource I could only take the data for 13 years.

\subsubsection{Sample Size}

Macroeconomic indicators plays vital role in any country economy, a minor fluctuation in this variable influence the universe of economy, so the regularity authority keeps very important role to control these fad economy indicators, to control these factors, regularity authority sets policies such like monetary policy, exchange rate, policy, foreign reserve policy and so on, in this research the time series data of 14 years was selected from January 302004 to February 102017 on monthly basis, whereas in this tenor the data of financial crisis is also included, Multiple Regression model is examined to test the hypothesis, entire data is collected from the reliable source, to test the multiple regression.

\subsubsection{Technique and Procedures}

This research is basically secondary research, number of researches have been conducted on the somehow same topic but it different zones and different time horizons, whereas the required data is only available on the archival data base sources such like Pakistan Stock Exchange (PSX), State Bank of Pakistan (SBP), Pakistan Bureau of Statistic (PBS), World Bank, International Monetary Foundation (IMF), and Bloomberg. However the data is collected from aforementioned sources which are very much authentic and reliable so that data of this research seems very authentic and reliable, and the data is time series data so EVIEWS version 9 is used to generate results, and make the sound illustration of this findings,

Multi Regression model is used along with the Least Square Method (SLM) to test the hypothesis at EVIEWS version 9.0, whereas independent variables are macroeconomics indicator (interest rate, inflation rate and exchange rate) and dependent variable is stock returns.

\subsubsection{Multiple Regression Model}

\section{$\mathrm{SR}=\mathrm{C}+\mathrm{IR}+\mathrm{INF}+\mathrm{ER}+\mathrm{Er}$}

Whereas below are the abbreviation of this equation.

$\mathrm{SR}=$ Stock Return

Stock return is calculated by this below formula.

Stock Return $=$ LN $(\mathrm{P} 1 / \mathrm{Po})$

$\mathrm{C}=$ Constant

$\mathrm{IR}=$ Interest Rate

$\mathrm{INF}=$ Inflation Rate

$\mathrm{ER}=$ Exchange Rate

ER is calculated like change in exchange rate with the equation of $\mathrm{ER}=\mathrm{LN}(\mathrm{ER} 1 / \mathrm{ER} 0)$
$\mathrm{Er}=$ Error Term

There are different ways to calculate inflation rate such like industrial production index (IPI), whole sale price index WPI), service price index, (SPI) and consumer price index (CPI), hence to calculate CPI in the Pakistan, a basket of commodities is made and have comparison with the price on that basket on yearly basis, this basket consist 374 items of the commodities with aggregate price level in 35 mega cities of Pakistan, although SPI in measure on the weekly basis which covers 17 mega cities of the Pakistan, WPI basically is measure on those item which are consumed on the primary and the secondary level, this information is directly collected from the country's wholesale market of the companies, this method may covers the mega group which comprised on 425 items of the commodities.

In this research Pak Rupee to American Dollar exchange rate is taken to find the relationship of exchange rate on the stock returns, it is very understood that the American Dollar is treated as international currency so at most foreign transaction this is used as currency exchange, if our beloved Country Pakistan export more we will get more PKR because Dollar rate is high enough in the Pakistan.

Interest Rate is the cost of lending and borrowing money, state bank of Pakistan (SBP) issue the monetary policy, in which interest rate keep very important worth, it is also nuts and bolts of economy of any country, interest rate may be nominal interest rate, real interest rate, or market Interest Rate, nominal interest rate is unadjusted to inflation hence real is adjusted with inflation rate, in this research 6 month KIBOR Rate is taken as proxy of the interest rate, KIBOR is The Karachi Interbank Offered Rate, or KIBOR, is the average interest rate at which term deposits are offered between prime banks in the Pakistani wholesale money market or interbank market.

\section{Results \& Discussion}

\section{Unit Root Test}

In the Econometrics and Statistic to normalize the data stationary the test which is applied, commonly known SR represent the stock returns, to make stock return stationary at 1 st difference ADF technique is used, in the above table the P-Value is $<0.05$ which means that data is stationary, so that null hypothesis is rejected the graph is also witnessed of data stationary, whereas in the graph it is crystal clear that the data is random and stationary, therefore after making the data stationary it can be used further to make regression model. As Dickey-Fuller $\mathrm{t}$-value in the negative sign at -10.44 so null hypotheses is rejected because it is refer by the dicky-fuller the more negative values there are the more chance would be there to reject null hypothesis.

Table 1.

\begin{tabular}{lcc}
\hline \multicolumn{3}{c}{ Unit Root Test (Augmented Dicky Fuller) } \\
\cline { 2 - 3 } & \multicolumn{2}{c}{ At Level } \\
\hline Interest Rate & t-statistic & Prob $^{*}$ \\
Inflation Rate & -11.311 & 0.00 \\
Exchange Rate & -5.497 & 0.00 \\
Stock Returns & -10.088 & 0.00 \\
\hline
\end{tabular}




\section{Interpretation;}

IR represent the Interest rate, to test IR stationary Augmented Dicky Fuller Test is used, hence this is common technique to make data random and stationary so that, if the data is stationary the model would be significant, without making data stationary the predicted model will be insignificant, to make data stationary interest rate was test by unit root test at 2 nd difference, as above give table show p-value at 0.000 and t-value at -11.31 , which indicate to reject null hypothesis of the unit root test and accept the alternative hypothesis, to support findings of the results the graph illustrate that the data is random and stationary.

INF represent Inflation rate, this was one of the volatile variable is this research, the data was collected before and after financial crisis which was 2008-2009 meanwhile the financial crisis where the most fluctuant is found in the inflation rate, so to make inflation rate data stationary unit root test is applied at 2 nd difference. Hence the p-value is $<0.05$ the value laying at 0.000 and $t$-value at -5.49 , which indicate that the null hypothesis of dickey-fuller test supposed to be rejected, hence as shown in the graph data seem random and stationary after applying unit root test.

ER Represent Exchange Rate, while financial Crisis there was very big impact on the exchange rate in Pakistan exchange rate is taken as change in to exchange rate, which was calculated like ER $=\mathrm{LN}(\mathrm{ER} 1 / \mathrm{ER} 0)$. Hence this study involves the data of before and after financial crisis. That's why the data of exchange rate was very scatter, to make it random and stationary, unit root test at 2nd difference was applied, and exchange rate P-value is $<0.05$ which is laying at 0.000 and t-statistic value is -10.08 , therefore null hypothesis is rejected and alternative is accepted which means that the data has been made stationary and random, even the graph illustrate data randomness and stationary.

Stock Returns was also found stationary, while the $\mathrm{P}$-value is less than 0.005 at the level which is indicative that stock returns have a systematic pattern for best fit in ordinary least square.

Table 2.

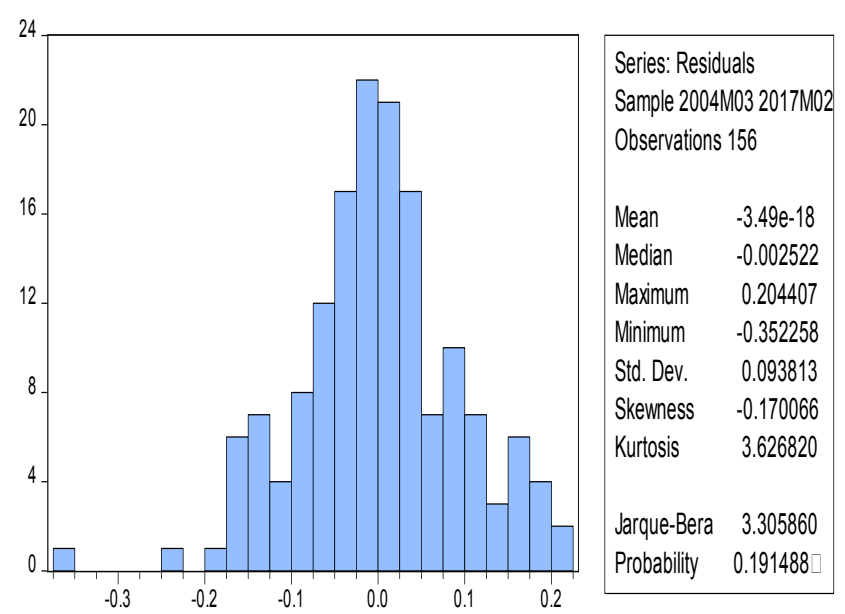

\section{Interpretation;}

In the secondary researches, the data is in very big quantity, so there is more chances to have unequal data distribution or abnormal data distribution, to get fix this problem before making the model, normal data distribution is checked by the Jarque-Bera test. Which witness the normal distribution of data with some specific parameters, to check normal distribution of the data Jarque-Bera offer hypothesis, the null hypothesis of Jarque-Bera H0: data is not normally distributed and the alternative hypothesis is the data is normally distributed, if the P-value is $<0.05$ fine so it represent that data is not normally distributed, or if the value is $>0.05$ so data us normally distributed, as above shown P-Value $>0.05$, which is laying at 0.19 , this number indicate that the entire data has been made stationary and this is normally distributed, further the graph also illustrate that the data is distributed equally,

Skewness and Kurtosis also represent that the aforementioned data is normally distributed however the value of kurtosis laying at 3.62 which seems to be little bid higher but this number is acceptable to perceive that the collected data is distributed equally. The value of Skewness and Kurtosis should be between $-3.5 \&+3.5$ as per the set criteria of Skewness and Kurtosis so the overall models along with the Jarque-Bera, Skewness, and kurtosis witness data is distributed equally.

Hence the given value of mean is $-3.49 \mathrm{e}$ which is showing the averages of entire 156 values, hence the value of mean is in negative due to unit root test, so it can be understand that most values coming nearer $-3.49 \mathrm{e}$, there very minor variation to mean of data, this variation is measure through the standard deviation tool, therefore the value of standard deviation is 0.09 which represent the numbers have very close similarities or very less deviation to each other's.

Table 3.

\begin{tabular}{cccc}
\hline \multicolumn{4}{c}{ Heterokesdasticity Test Breuch-Peagan-Gotfrey } \\
\hline F-Statistic & 1.27 & Prob. F (3,152) & 0.28 \\
Obs R Squared & 3.82 & Prob. Chi-Square (3) & 0.28 \\
Scaled Explained SS & 4.77 & Prob. Chi-Square (3) & 0.18 \\
\hline
\end{tabular}

\section{Interpretation;}

To measure Heteroscedasticity in the statistic a technique namely Breusch-Pagan-Godfrey (BPG) is generallu used, Heteroscedasticity means the data is data is scatter enough, if the ordinary least square model is run so Heteroscedasticity data can ruin the result, or it may misrepresent the findings, this test is used while making regression model. As the null hypothesis of the BPG test is the data is homoscedastic, which is ideal while conducting regression model, so accept the null hypothesis the P-value should be $>0.05$, the value come at this parameter so data would be considered homoscedastic, which ideal in any regression model of vice versa, and the alternative hypothesis of the BGP test is the data is heteroscedasticity which shows data is differently scattered, which is assumed dangerous to run regression model, heteroscedasticity can ruin the result of the multi regression findings, hence to accept heteroscedasticity the P-value of the alternative hypothesis should be $<0.05$, the Probability chi-square value is 0.1890 which is $>0.05$, this number indicate that the data is Homoscedastic, which is supposed to be ideal while conducted any multi regression model, therefore the finding or the results of multi regression model will be considered reliable and true results. 
Table 4.

\begin{tabular}{ccccc}
\hline Variable & Coefficient & Std. Error & t-Statistic & Prob. \\
\hline C & 0.01 & 0.00 & 7.71 & 0.00 \\
IR & -0.30 & 0.20 & -1.50 & 0.14 \\
INF & -0.09 & 0.09 & -1.10 & 0.27 \\
ER & 0.03 & 0.03 & 0.92 & 0.36 \\
\hline
\end{tabular}

\section{Interpretation;}

To avoid heteroscedasticity, BPG model is used whereas the null hypothesis of BPG is the data is homoscedastic, if the $\mathrm{P}$-value is $<0.05$ null hypothesis cannot be accepted, although the alternative hypothesis of BPG is the data is heteroscedastic, so if the P-Value is $<0.05$ null hypothesis is accepted, as the above given $\mathrm{P}$-value of Interest rate (Independent Variable) is 0.13 , which is showcase that the data of interest rate is homoscedastic, this is ideal to test regression model, Inflation Rate (Independent Variable) enjoys the P-value at 0.27 whereas null hypothesis of BPG is accepted, this number of P-value indicate that the data is not scatter, the number of inflation rate is homoscedastic, so this can be perceive ideal to run regression model, Exchange Rate (Independent Variable) P-value is 0.35 this is also homoscedastic data so all the Independent variables having homoscedastic values which is perceive ideal, along with this value the regression model would be considered predictable.

Table 5.

\begin{tabular}{lcccc}
\hline Variable & Coefficient & Std . E rro r & t-S ta tis tic & Prob. \\
\hline IR & $(3.00)$ & 1.34 & $(2.23)$ & 0.03 \\
IN F & $(0.23)$ & 0.57 & $(0.40)$ & 0.69 \\
ER & $(0.55)$ & 0.22 & $(2.49)$ & 0.01 \\
C & - & 0.01 & $(0.00)$ & 1.00 \\
\hline
\end{tabular}

\section{Interpretation;}

To test the hypothesis Multiple Regression method is used, with the margin of error at 5\% and the confidents interval is $95 \%$ of the model, therefore the value of Interest Rate is 0.027 , this value witness to accept the alternative hypothesis, the value of coefficient is -3.000 , which showcase that there is significant negative relationship between interest rate and stock returns, but the relationship not that strong, the P-vale of Inflation Rate is 0.68 which compel to accept null hypothesis, and the value of coefficient value is laying on -0.227 which show negative correlation between inflation rate and stock returns but this is insignificant,

Exchange Rate P-value is laying at 0.01 and coefficient value is -0.55 which shows there negative significant relation between exchange rate and stock returns, but this relationship is not strong enough because the value of coefficient is less than 1 which means there is weak negative significant relationship between exchange rate and stock returns.

Hence the findings reveal that there are two independent variable (Interest Rate and Exchange Rate) which have negative significant relationship with the dependent variable (Stock Returns), and there is one independent variable (Inflation Rate) which is having negative but insignificant relationship with the dependent variable (Stock Returns).
Table 6.

\begin{tabular}{|c|c|c|c|}
\hline \multicolumn{5}{|c|}{ Model Summary } \\
\hline R-s quared & 0.07 & Mean dependent var & - \\
\hline Adjus ted R-s quared & 0.05 & S.D. dependent var & 0.10 \\
\hline S.E. of regres s ion & 0.09 & Akaike info criterion & $(1.85)$ \\
\hline Sum squared resid & 1.36 & Schwarz criterion & $(1.77)$ \\
\hline Log likelihood & 148.31 & Hannan-Quinn criter. & $(1.82)$ \\
\hline F-s tatis tic & 3.58 & Durbin-Watson stat & 2.75 \\
\hline Prob (F-s tatis tic) & 0.02 & & \\
\hline
\end{tabular}

\section{Interpretation;}

Adjusted R-Square represent that how much the independent variable explain the dependent variable or what is the contribution of independent variable into the dependent variables, therefore aforementioned value of Adjusted R-Square is 0.047 or $4.7 \%$, this number indicates that the independent variables (interest rate, inflation rate, and exchange rate) explain the dependent variable (stock returns) at $4.7 \%$, so there are economic indicators who explain the dependent variables at $95.3 \%$, it is concluding by the value of Adjusted R-Square that there very least impact of independent variables on dependent variable.

ANOVA shows the model fit, ANOVA represent either the predicted model is significant or not, if the F-statistic's $\mathrm{P}$-value of ANOVA is $<0.05$ so alternative hypothesis is accepted which may be the predicted model is significant or vice versa. F-statistic's P-Value is laying at 0.015 which is $<0.05$ so the ANOVA table confirms that the predicted model is significant, at $5 \%$ of significant level.

To measure autocorrelation is the residual from the statistic regression analysis Durbin Watson Technique is used, the number of durbin-watson test measure the correlation amongst the residuals, the value are always between 0 to 4 if the value is 2, it explains that there no autocorrelation which is good to check the significant of the predicted model, and the vale is between 0 to 1 so there is positive autocorrelation, and if the value is between 3 to 4 so there is negative autocorrelation, neither positive or negative correlation is acceptable for the least square regression model, there should be any autocorrelation because autocorrelation may biased the results of the regression model, hence above table shows the value of durbin-watson at 2.75 which means that there is no autocorrelation in the residuals.

\section{Discussion \& Conclusions}

\subsection{Discussion}

This research was conducted to find out the impact of interest rate, inflation rate and exchange rate on the KSE100 stock returns; multiple regression method was used to determine the relationship.

Inflation rate: results indicate an insignificant negative relationship between inflation rate and stock market returns, thus, inflation rate is not deemed to significantly influence stock market returns,

Interest rate: The findings reveal that there is negative significant relationship between the interest rate and the stock returns. A rational investor would prefer to invest in an avenue that offers higher risk adjusted return. Given a 
low interest rate scenario in a country, fixed income securities will offer lower returns than stock market thus; an investor would rather deploy his resources in stock and garner higher return. Likewise, in high interest rate scenario investor's flock towards safe heaven investments (fixed income securities) instead of stock market that is relatively risky.

Exchange Rate: Exchange rate has a significant negative relationship with stock returns. For example, assume there are only two countries in the world, namely Country A and Country B. Returns in Country B are higher than Country A; an investor in Country A would invest in Country B to garner higher returns. Therefore, supply of Country A's currency will increase as the investor converts money to invest in Country B, exerting downward pressure of Country A's currency. Thus, Country B's currency would appreciate relative to Country A.

\subsection{Conclusion}

Theoretically, the country offering higher interest rate will witness currency appreciation relative to the based currency, ceteris paribus. However, in practice impact of macroeconomic factors tend to outplay this theoretical relationship as government manipulates various tools to meet economic objectives. A case in point is Pakistan where although the stock market has witnessed increment but it has failed to lure foreign investment. During the ongoing year, stock market is expected to rise up to 55,000 points whereas foreign reserves are anticipated to remain stagnant at \$23-24billion., which is match with the past research, as Khan, et al. [1] conducted research, to find out the relationship between interest rate, inflation rate and exchange rate on stock return, whereas they took the sample size of 10 years from 31st July to 30th 2010 to test hypothesis, multiple regression model was used to test the hypothesis, and the findings reveal that there is there is weak relationship between the Independent variables \& Dependent Variable variables, the impact of interest rate and inflation rate is insignificant, although the impact of exchange rate is negative on the stock return, or it can be said like there is inverse relationship between exchange rate and stock returns.

Bashir and Hassan [2], together conducted a research, to find out the relationship between interest rate and stock returns in the UAE the time series data was covering the period of 1990 to 1994 to test the hypothesis, simple OLS test was applied, findings reveal that interest rate fluctuation had significant invers (negative) relationship with stick returns of the banking sector.

Nishat and Shaheen, [3] conducted a research to find out the relationship between the macro economic variables and KSE-100 stock returns, hence they took data on quarter wise basis from the 1973 to 2004 to test the hypothesis, macroeconomics indicators are Industrial Production Index, Inflation, Broad Money, Value of an Investment and Money Market rate applied with error correction model and Granger Causality test was also applied, findings reveal the long run relationship amongst these variables, it is further found that the IPI and Inflation rate were highest positive and negative factors respectively, there was also causal relationship between interest rate and stock returns. So the finding of this research is reliable which is confirming by the past researches. due to lake of resource this research could not cover the entire economic indicators and also could not stretched the tenor of 13 years, if any future research is conducted, so more variables can be taken to generate better results.

\section{Recommendations}

Recommendation for investor while investing into the Pakistan's stock market, must analyze interest rate and exchange rate, this phenomenal behavior of the investor either local or foreign, they want to less risk and more return, so the plate farm of investing money either the risk bearing securities or risk free securities, if the interest rate is high so there would be less return from stock market, in this case investing into stock market seems to be lucrative or vice versa,

Hence high exchange rate discourage the investors to invest in the stock market so it is recommended that if the exchange rate is high so do analysis of the exchange rate patterns, and make projection for future exchange rate before investing into Pakistan Stock Market, this prudent analysis may create better opportunities to earn the lucrative profits,

Recommend for the future researches, they may take more variables to measure the relationship between the macroeconomic factors and stock return, further they may stretch the time horizon of the research.

\section{References}

[1] Khan, Z., Khan, S., Rukh, L., Imdadullah, K., \& Rehman, W. (2012). Impact of interest rate, exchange rate and inflation on stock returns of KSE 100 index. International Journal of Economics and Research, 3(5), 142-155.

[2] Bashir, A., \& Hassan, A. (1997). Interest Rate Sensitivity and Stock Returns in the United Arab Emirates. Journal of King Saud University, 9, 79-89.

[3] Nishat, M., Shaheen, R., \& Hijazi, S. T. (2004). Macroeconomic Factors and the Pakistani Equity Market [with Comments]. The Pakistan Development Review, 619-637.

[4] Ali, T. M., Mahmood, M. T., \& Bashir, T. (2015). Impact of interest rate, inflation and money supply on exchange rate volatility in Pakistan. World Applied Sciences Journal, 33(4), 620-630.

[5] Mbulawa, S. (2015). Effect of macroeconomic variables on economic growth in Botswana.

[6] Muriuki, K. (2014). The effect of inflation and interest rates on stock market returns of firms listed at the Nairobi securities exchange. Unpublished master's thesis. University of Nairobi.

[7] Thang, F. (2009). Impact of interest rate and exchange rate on the stock market index in Malaysia: a cointegration analysis. Unpublished master's thesis, Universiti Sains, Penang, Malaysia. Retrieved from

http://eprints.usm.my/25494/1/IMPACT OF INTEREST RATE AND_EXCHANGE_RATE_ON.pdf.

[8] Kanwal, S., \& Nadeem, M. (2013). The impact of macroeconomic variables on the profitability of listed commercial banks in Pakistan. European journal of business and social sciences, 2(9), 186-201.

[9] Maysami, R. C., Loo, S., \& Koh, T. (2004). Co-movement among sectoral stock market indices and cointegration among dually listed companies. Jurnal Pengurusan, 23, 33-52.

[10] Hyde, S. (2007). The response of industry stock returns to market, exchange rate and interest rate risks. Managerial Finance, 33(9), 693-709. 
[11] Blanchard, O. J.et all. (1981). Findings, the Stock Market, and Interest Rates. The American Economic Review, 71 (1), 132-143.

[12] Kaul, G. (1987). Stock Returns And Inflation. Journal of Financial Economics, 18 (1), 253-276.

[13] Anderson, J. M. (1990). Micro-macro linkages in economic models. Microsimulation techniques for tax and transfer analysis. Urban Institute, Washington, DC.

[14] Lobo, B. J. (2000). Asymmetric Effects of Interest Rate Changes on Stock Prices. The Financial Review, 35, 125-144.

[15] Devereux, M. Lane, B. (2006), Exchange Rate and Monetary Policy Emerging Market Economics, The Economic Journal, 478506.

[16] Khrawish, H. A., Siam, W. Z., \& Jaradat, M. (2010). The relationships between stock market capitalization rate and interest rate: Evidence from Jordan. BEH - Business and Economic Horizons, 2 (2), 60-66.
[17] Rano, S. U., \& Bayero, A. (2010). Does inflation has an impact on Stock Returns and Volatility? Evidence from Nigeria and Ghana. 1-17

[18] Mundell, R. (1963). Inflation and real interest. Journal of Political Economy, 71(3), 280-283.

[19] Aydemir, O., \& Demirhan, E. (2009). The relationship between stock prices and exchange rates: Evidence from Turkey. International Research Journal of Finance and Economics, 23(2), 207-215.

[20] Muhammad, N., Rasheed, A., \& Husain, F. (2002). Stock prices and exchange rates: Are they related? evidence from south asian countries [with comments]. The Pakistan Development Review, 535-550.

[21] Chaudhry, M. A., \& Young, R. A. (1990). Economic impacts of alternative irrigation water allocation institutions: Pakistan's warabandi system. Economic impacts of alternative irrigation water allocation institutions: Pakistan's warabandi system., 395-410.

C The Author(s) 2019. This article is an open access article distributed under the terms and conditions of the Creative Commons Attribution (CC BY) license (http://creativecommons.org/licenses/by/4.0/). 